\title{
Morphology, morphometry and some aspects of clinical anatomy in the skull and mandible of Sharri sheep
}

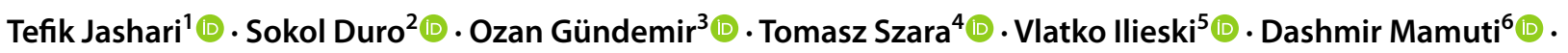 \\ Om Prakash Choudhary ${ }^{7}$ (D)
}

Received: 10 May 2021 / Accepted: 28 October 2021 / Published online: 17 November 2021

(c) The Author(s) 2021

\begin{abstract}
The aim of this study was to investigate and record data on the morphometrical parameters of the skull and mandible in Sharri sheep. We have evaluated 34 skulls (24 females and 10 males) of Sharri sheep (Ovis aries), a local breed of sheep from Northern Macedonia. Fifty-one measurements were evaluated in total: 37 parameters on the skull and 14 parameters on the mandible. The results of the study show that, in general, the morphology and morphometric parameters of the skull and mandible, of Sharri sheep are similar to those of other sheep breeds with few differences. The mean skull length (SL), skull height (SH), distance between two supraorbital foramina (DBTSF), orbital length (OL), mandible length (ML) and Sharri sheep diastema (D) were $247.47 \pm 13.12 \mathrm{~mm}, 104.71 \pm 6.21 \mathrm{~mm}, 50.73 \pm 3.44 \mathrm{~mm}, 41.21 \pm 1.99 \mathrm{~mm}, 185.91 \pm 13.33 \mathrm{~mm}$ and $45.81 \pm 3.73 \mathrm{~mm}$, respectively. The results also show that out of 51 parameters, only 13 show a statistically significant difference between females and males, particularly the distance of akrokranion to opisthion (AO), articular surface length of mandibular condyle (ASL) and anterior limit of the mandibular foramen to cranial border of ramus mandible (RBMFRMRM). The findings of this study are important in many aspects: morphologically, morphometrically and especially clinically, during surgical interventions in the head region. With a lack of information in current literature on the investigated parameters in this sheep breed, the present data are a solid basis for further studies in comparative anatomy with other ruminants and in other areas such as zooarchaeology and animal welfare.
\end{abstract}

Keywords Cranium $\cdot$ Mandible $\cdot$ Orbital measurement $\cdot$ Osteometry

Tomasz Szara

tomasz_szara@sggw.edu.pl

1 Institute of Graduate Studies, Istanbul UniversityCerrahpasa, Istanbul 34500, Turkey

2 Faculty of Veterinary Medicine, Agricultural University of Tirana, 1000 Tirana, Albania

3 Department of Anatomy, Faculty of Veterinary Medicine, Istanbul University-Cerrahpasa, Istanbul 34500, Turkey

4 Department of Morphological Sciences, Institute of Veterinary Medicine, Warsaw University of Life Sciences, 02-776 Warsaw, Poland

5 Faculty of Veterinary Medicine, University Ss. Cyril and Methodius in Skopje, Skopje, Republic of North Macedonia

6 Faculty of Agriculture and Biotechnology, University of Tetovo, Tetovo, Republic of North Macedonia

7 Department of Veterinary Anatomy and Histology, College of Veterinary Sciences and Animal Husbandry, Central Agricultural University (I), Selesih, Aizawl 796015, Mizoram, India

\section{Introduction}

Sharri or Sharplaninska pramenka sheep are a local breed of sheep (Ovis aries Linnaeus, 1758) found in Northern Macedonia, and they represent almost $30 \%$ of the total sheep population in this country. Sharri sheep are a unicolor, white breed with a long tail and triple production (milk-meat-wool) (Dzabirski et al. 2013). This strain has the advantages of natural hardiness, grazing abilities, and are well adapted to a cold mountain climate, since this breed lives near the Sharri mountains. The rams are horned and reach about $44-45 \mathrm{~kg}$, and ewes are polled and reach about 30-32 kg (Kugler 2009; Dzabirski et al. 2013; Bytyqi et al. 2014).

The structure of the skull is a unique feature of each animal, allowing for the distinguishment of not only species and breeds, but also individuals. Sexual dimorphism is strongly manifested in the skeleton of the head of ruminants (Kobryńczuk et al. 2008b). The results of many studies made on these bones are a great contribution in areas of taxonomy, 
comparative anatomy (Özcan et al. 2010; Karimi et al. 2011; Mohamed et al. 2016; Dalga et al. 2018) and in the clinical veterinary practice, surgery, implantology, stereotaxic practices, animal welfare, etc. (Dalga, and Aslan 2020; Wehausen and Ramey 2000). Current morphometric study results can be used to determine the type of bone obtained in excavation studies. Assumptions can then be made about the history of the excavation area, as well as the livestock conditions of that time. This is done with morphological determinations using morphometric results (Onar et al. 2015). In addition, differences between the sexes were found on the skull and mandible. With these differences, gender analysis can be made by looking at the measurement points (Marzban et al. 2018; Gündemir et al., 2020).

The skeleton of the head consists of two parts. The first part surrounding the brain - neurocranium and the second part surrounding the oral and nasal cavities - splanchnocranium are composed by different paired and unpaired bones (König and Liebich 2020; N. A. V. 2017). Mandibles provide support for lower incisive teeth, premolars, molars, and the entire base structures of the mouth.

Sheep under natural conditions often suffer from problems such as: abscesses in the jaw, damage to and loss of teeth, fractures of the mandible, temporomandibular joint damages etc. In these conditions, preventive or even surgical interventions are necessary. The success of which depends on a very good knowledge of clinical anatomy of the mandible, including: mental and mandibular foramina which have a fundamental importance in regional anesthesia.

No anatomical studies have been carried out so far in Sharri sheep. With this study, we aim to show and record morphological, morphometric and clinically relevant data for the skull of this breed, the number of which is heading towards the limit of extinction.

\section{Material and methods}

Skulls and mandibles of 24 females and 10 male adult Sharri sheep were used in this study. The research material was collected from Northern Macedonia and approved by the Ethics committee of University of Tetovo, North Macedonia (Decision No: 25-4811).

The skulls of the sheep were obtained after slaughter. Bones were cleaned by standard procedures after the skin and soft tissue were removed. Measurements were made based on the instructions of von den Driesch (1976) in own modification. In this study we have measured 51 parameters in total: 37 parameters on the skull and 14 on the mandible. Also, we have evaluated five indices of the skull. All measurements were taken in millimeters with a digital caliper $( \pm 0.2 \mathrm{~mm})$. The photographs of the samples were made with a Samsung photo camera NX210 20.3 MP.

\section{Skull measurements (Figs. 1, 2, 3 and 4)}

1. Skull length (SL) - max. length of the skull from the rostral tip of the incisive bones (Prosthion) to the external occipital protuberance

2. Cranial length (CL) - distance from the nuchal crest to the junction of the left and right nasofrontal sutures on the median plane

3. Max. width of neurocranium (MWNC) - distance from the most lateral point of the cranial cavity on the left to the most lateral point of the cranial cavity on the right

4. Facial length (FL) - distance from the junction of the left and right nasofrontal sutures in the median plane to the rostral tip of the incisive bones (Prosthion)

5. Facial width (FW) - distance between the caudal extents of the orbital margin (Ectorbital - Ectorbital)
Fig. 1 Parameters on the dorsal view of the skull of Sharri sheep. 1. Skull length (SL); 2. Cranial length (CL); 3. Maximum width of neurocranium (MWNC); 4. Facial length (FL); 5. Facial width (FW); 6. Entorbitale-Entorbitale (EE); 7. Length of the inter frontal suture (LIFS); 8. Bregma to Akrokranion (ba); 9. Greatest length of nasal bone (GLNB); 10. Incisive bone to Nasal Bone (IBNB); 11. Prefacial width (PFW); 12. Distance between two supraorbital foramina (DBTSF)

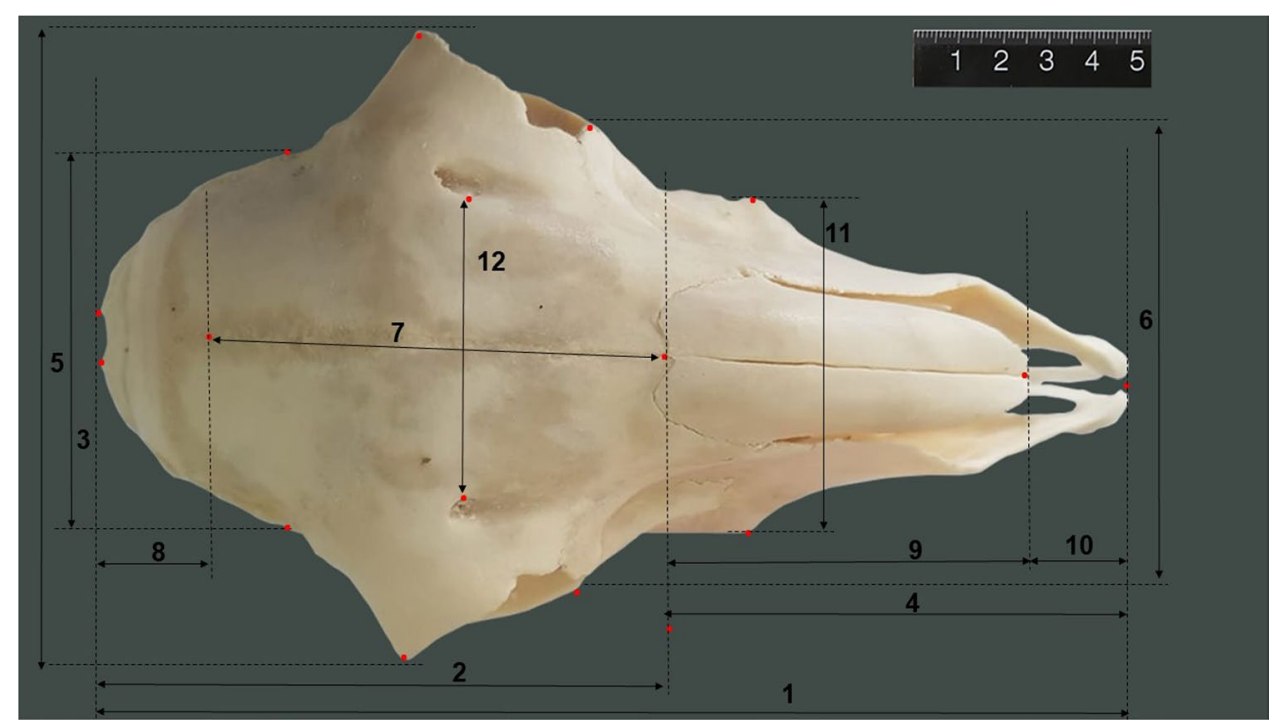




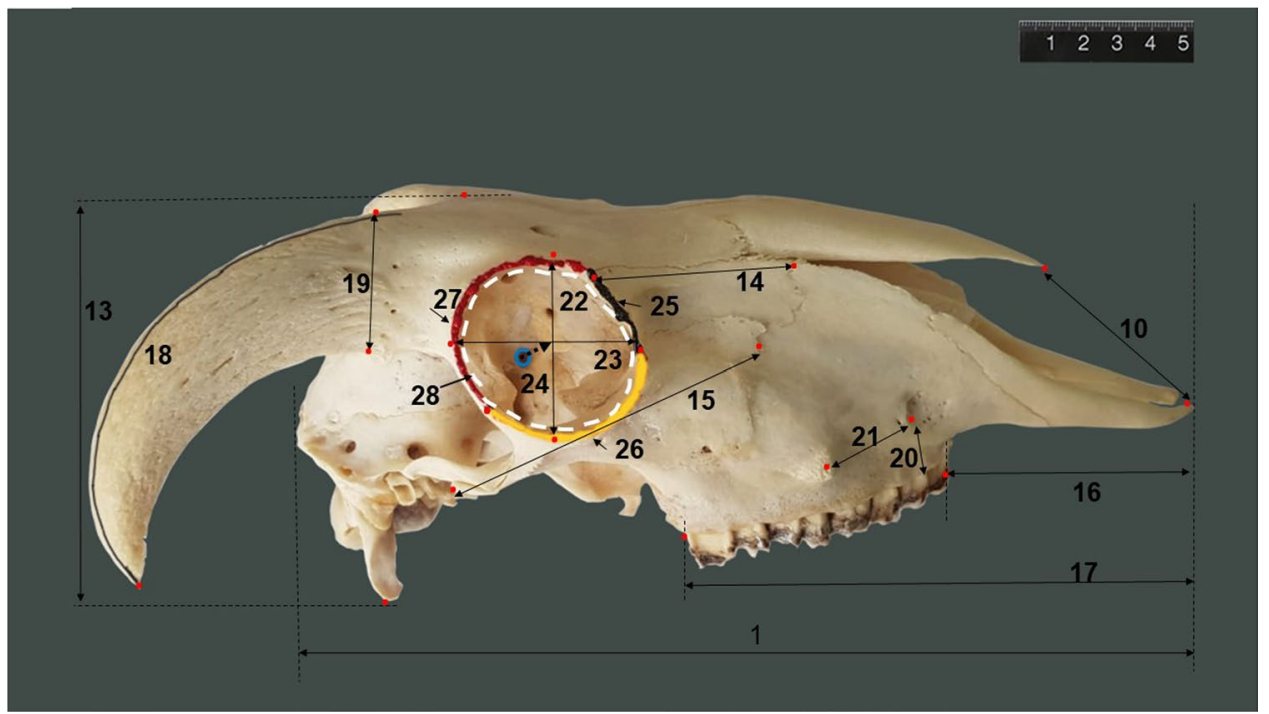

Fig. 2 Parameters on the lateral view of the skull of Sharri sheep. 1. Skull length (SL); 10. Incisive bone to nasal bone (IBNB); 13. Skull height (SH); 14. Greatest length of the lacrimal bone (GLLB); 15. Greatest length of the zygomatic bone (GLZB); 16. Distance prosthion to PM1 (PPM1); 17. Dental length (DL); 18. Cornual process length (CPL); 19. Cornual process width (CPW); 20. Infraorbital foramen to alveolar margin (IFAM); 21. Facial tuberosity to infraor-

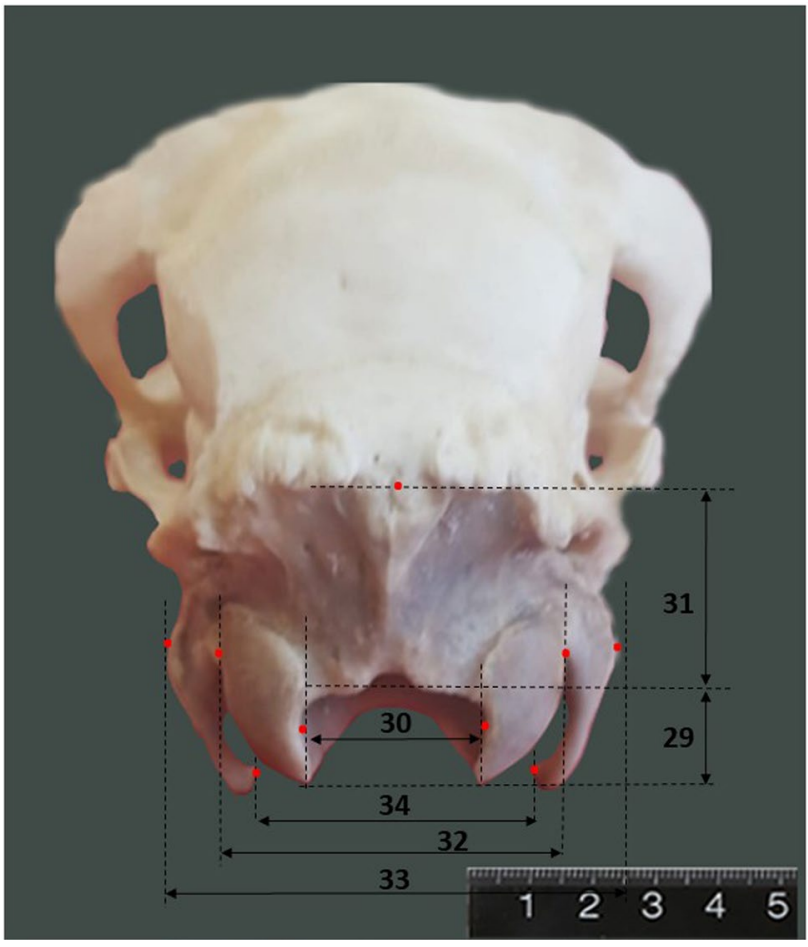

Fig. 3 Parameters on the nuchal view of the skull of Sharri sheep. 29. Foramen magnum height $(\mathrm{FMH}) ; 30$. Foramen magnum width (FMW); 31. Akrokranion to Opisthion (AO); 32. Inter condylar width (ICW); 33. Inter base paracondylar width (IBPCW); 34. Inter paracondylar width (IPCW) bital foramen (FTIF); 22. Orbital length (OL); 23. Orbital width (OW); 24. Orbital depth (OD); 25. Orbital margin of lacrimal bone (OMLB); 26. Orbital margin of zygomatic bone (OMZB); 27. Orbital margin of frontal bone (OMFB); 28. Orbit perimeter (OP). Red line-Frontal bone margin; black line-lacrimal bone margin; yellow line- zygomatic bone margin; white discontinued line-orbit perimeter; blue point- optic foramen;

6. Entorbitale-Entorbitale (EE) — the width between the rostral borders of the orbits

7. Length of the interfrontal suture (LIFS)

8. Bregma to Akrokranion (BA) —distance from parietofrontal suture to nuchal line

9. Greatest length of nasal bone (GLNB)

10. Incisive bone to nasal bone (IBNB) - distance from the rostral tip of the incisive bones (Prosthion) to the tip of septal process

11. Prefacial width (PFW) - the distance between two facial tuberosities

12. Distance between two supraorbital foramina (DBTSF)

13. Skull height (SH) - from the level of the highest point of the frontal bone to the tip of the paracondylar process

14. Greatest length of the lacrimal bone (GLLB)

15. Greatest length of the zygomatic bone (GLZB)

16. Distance from Prosthion to PM1 (PPM1) - the distance between the rostral tip of incisive bones to first premolar tooth

17. Dental length (DL) - distance from the rostral tip of incisive bones (Prosthion) to caudal border of the third molar tooth

18. Cornual process length (CPL) - the distance from the base to the tip of the cornual process

19. Cornual process width (CPW) - the transverse width of the proximal part of the cornual process

20. Infraorbital foramen to alveolar margin (IFAM) 
Fig. 4 Parameters on the ventral view of the skull of Sharri sheep. 16. Distance Prosthion to PM1 (PPM1); 17. Dental length (DL); 35. Skull width (SW); 36. Greatest palatal width (GPW); 37. Upper molar row from PM1 - M3 (UMR)

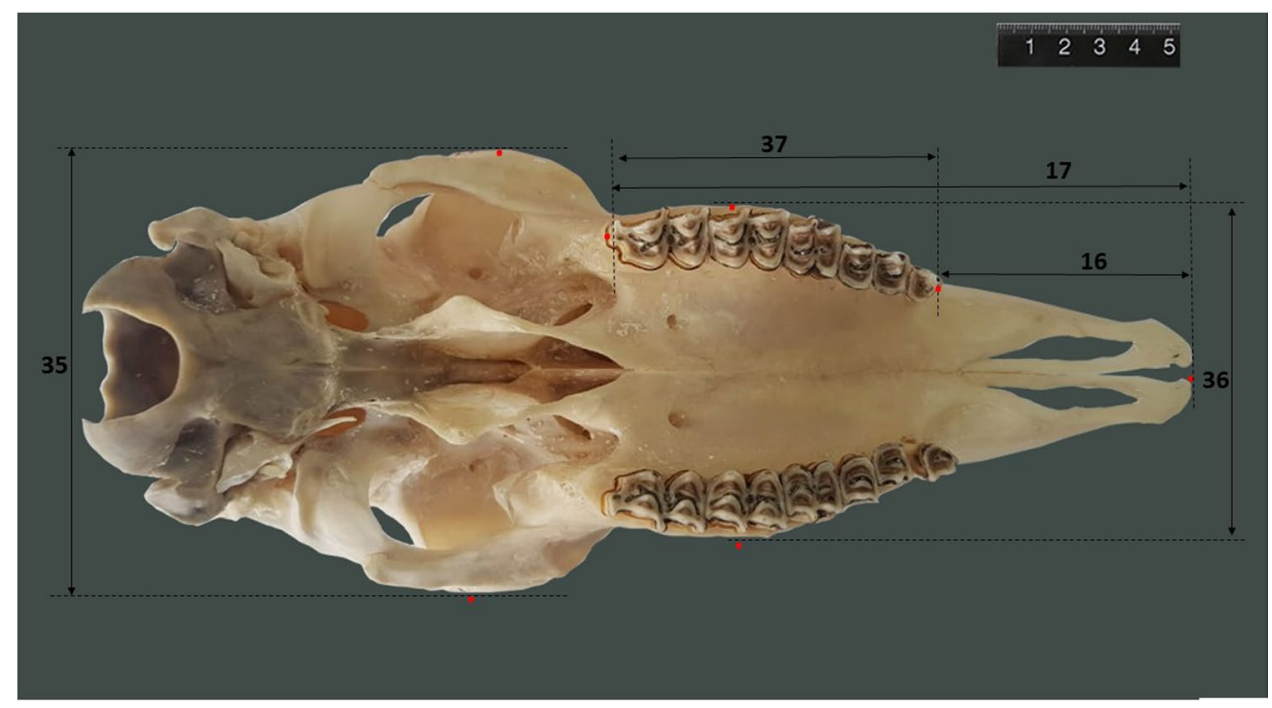

21. Facial tuberosity to infraorbital foramen (FTIF)

22. Orbital length (OL)

23. Orbital width (OW)

24. Orbital depth (OD)- from the optic foramen to the central point of the orbit

25. Orbital margin of lacrimal bone (OMLB)

26. Orbital margin of zygomatic bone (OMZB)

27. Orbital margin of frontal bone (OMFB)

28. Orbital perimeter (OP)

29. Foramen magnum height $(\mathrm{FMH})$-distance between the midpoints of the dorsal and ventral rims of the foramen magnum

30. Foramen magnum width (FMW) - maximum width between two occipital condyles

31. Akrokranion to Opisthion (AO) - distance from the caudoventral projection of the nuchal crest to the upper rim of the foramen magnum

32. Intercondylar width (ICW) — width between the lateral borders of the occipital condyles

33. Inter base paracondylar width (IBPCW) - the distance between the bases of the paracondylar processes

34. Inter paracondylar width (IPCW) - the greatest width between the ventromedial end of the paracondylar processes

35. Skull width (SW) - maximum breadth between two zygomatic arches

36. Greatest palatal width (GPW) - the distance between the most outer points of the two maxillary alveolar processes

37. Upper molar row from PM1 - M3 (UMR)

\section{Mandible measurements (Figs. 5 and 6)}

1. Mandible length (ML) - from the level of the rostral border of the first incisor alveolus the caudal border of ramus of mandible

2. Maximum mandible height (MMH) - from the ventral border of the mandible to the highest point of the coronoid process (Gonion ventrale - Coronion)

3. Mandibular base to condylar process (MBCP) -the distance from the ventral border of the mandible (Gonion) to the highest point of the condylar process

4. Mandibular notch to coronoid process (MICP) - the distance from the mandibular notch to the highest point of the coronoid process

5. M3 to mandibular angle (M3MA) - the distance from third molar tooth to the angle of the mandible

6. Articular surface length (ASL) - the length of the articular surface of the condylar process

7. First incisor tooth to mandibular angle (FITMA) - the distance from the first incisive tooth to the angle of the mandible

8. First incisor tooth to first premolar (FITFPm) - the distance between first incisor to the first premolar tooth

9. Lateral alveolar root to mental foramen (LARMF) shortest distance from the mental foramen to the lateral extent of the corner incisor alveolus

10. Diastema (D) - from caudal border of the corner incisor alveolus to rostral border of first premolar alveolus

11. Lower molar row from PM1 to M3 (LMR) - the length between first premolar tooth and third molar tooth of the mandible

12. Rostral border of the mandibular foramen to rostral margin of ramus mandible (RBMFRMRM) - the distance between the rostral limit of the mandibular foramen to the rostral margin of the ramus of mandible 
Fig. 5 Parameters on the lateral view of the mandible of Sharri sheep. 1. Mandible length (ML); 2. Maximum mandible height (MMH); 3 . Mandibular base to condylar process (MBCP); 4. Mandibular notch to coronoid process (MICP); 5. M3 to mandibular angle (M3MA); 6. Articular surface length (ASL); 7. First incisor tooth to mandible angle (FITMA); 8. First incisor tooth to first premolar (FITFPm); 9. Lateral alveolar root to mental foramen (LARMF); 10. Diastema (D); 11. Lower molar row from PM1 to M3 (LMR)

Fig. 6 Parameters on the medial view of the mandible of Sharri sheep. 1. Mandible length (ML); 2. Maximum mandible high (MMH); 11. Lower molar row from PM1 to M3 (LMR); 12. Rostral border of the mandibular foramen to rostral margin of ramus mandible (RBMFRMRM); 13. Mandibular foramen to mandible angle (MFMA); 14. Mandibular foramen to mandible caudal margin (MFMCM)
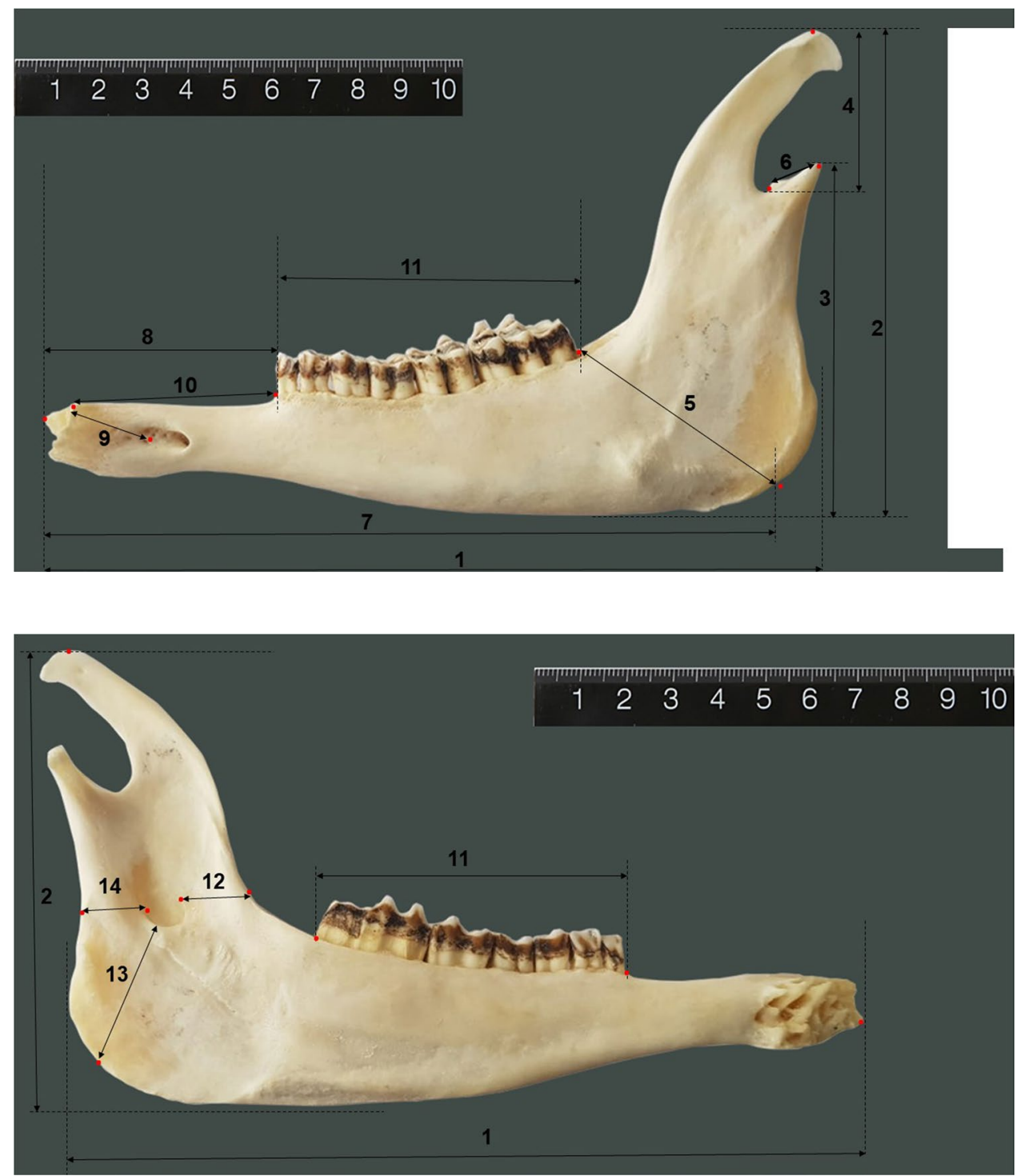

13. Mandibular foramen to mandible angle (MFMA) - the distance from mandibular foramen to mandibular angle

14. Mandibular foramen to mandible caudal margin (MFMCM) - the caudal limit of the mandibular foramen to the caudal margin of ramus mandible

\section{The indices of cranium and the orbit}

1. Skull Index $(\mathrm{SI})$ : skull width $(\mathrm{SW}) \times 100 /$ skull length (SL)

2. Cranial Index (CI): max. width of neurocranium $(\mathrm{MWNC}) \times 100 /$ cranial length $(\mathrm{CL})$

3. Facial Index $(F I)$ : facial width $(F W) \times 100 /$ facial length (FL)
4. Foramen Magnum Index (FMI): foramen magnum height $(\mathrm{FMH}) \times 100 /$ foramen magnum width $(\mathrm{FMW})$

5. Orbital Index $(\mathrm{OI})$ : orbital width $(\mathrm{OW}) \times 100$ /orbital length $(\mathrm{OL})$

\section{Statical analysis}

Means and standard deviations of all measurements were calculated for both males and females. Independent $t$-test was used to reveal the differences between genders. $P$ values are given in the results tables. The correlations between the measurements examined in the study were examined by using Pearson correlation coefficients. SPSS (version 22) software package was used for the statistical analysis. 
Table 1 Measurements of the skull of Sharri sheep

\begin{tabular}{|c|c|c|c|c|c|c|c|c|}
\hline \multirow[t]{2}{*}{$\mathrm{N}^{\mathrm{o}}$} & \multirow{2}{*}{$\begin{array}{l}\text { Dimension } \\
(\mathrm{mm})\end{array}$} & \multicolumn{2}{|l|}{ Total } & \multicolumn{2}{|l|}{ Female } & \multicolumn{2}{|l|}{ Male } & \multirow[t]{2}{*}{$p$ value } \\
\hline & & Mean & SD & Mean & SD & Mean & SD & \\
\hline 1 & Skull length (SL) & 247.47 & 13.12 & 248.17 & 9.73 & 245.80 & 19.62 & NS \\
\hline 2 & Skull width (SW) & 103.47 & 5.91 & 103.75 & 4.09 & 102.81 & 9.20 & NS \\
\hline 3 & Maximum width of neurocranium (MWNC) & 64.95 & 2.95 & 65.22 & 2.57 & 64.29 & 3.79 & NS \\
\hline 4 & Facial length (FL) & 145.95 & 10.92 & 146.18 & 8.01 & 145.38 & 16.52 & NS \\
\hline 5 & (Facial width) $(\mathrm{FW})$ & 119.47 & 5.78 & 120.32 & 4.86 & 117.42 & 7.45 & NS \\
\hline 6 & Entorbitale-Entorbitale (EE) & 89.29 & 4.83 & 89.15 & 4.36 & 89.60 & 6.07 & NS \\
\hline 7 & Length of the interfrontal suture (LIFS) & 88.73 & 5.54 & 88.53 & 5.37 & 89.20 & 6.18 & NS \\
\hline 8 & Bregma to Akrokranion (BA) & 49.11 & 3.20 & 49.95 & 2.42 & 47.09 & 4.02 & $*$ \\
\hline 9 & Greatest length of nasal bone (GLNB) & 94.93 & 9.60 & 93.74 & 8.66 & 97.78 & 11.55 & NS \\
\hline 10 & Incisive bone to nasal bone (IBNB) & 55.39 & 5.18 & 56.67 & 4.16 & 52.32 & 6.28 & $*$ \\
\hline 11 & Pre-facial width (PFW) & 75.24 & 5.65 & 76.16 & 4.30 & 73.02 & 7.87 & NS \\
\hline 12 & Distance between two supraorbital foramina (DBTSF) & 50.73 & 3.44 & 50.58 & 2.58 & 51.08 & 5.11 & 0,71 \\
\hline 13 & Skull height (SH) & 104.71 & 6.21 & 103.38 & 3.03 & 107.91 & 10.10 & NS \\
\hline 14 & Greatest length of the lacrimal bone (GLLB) & 51.46 & 3.60 & 51.29 & 3.38 & 51.86 & 4.25 & NS \\
\hline 15 & Greatest length of the zygomatic bone (GLZB) & 87.77 & 5.09 & 87.57 & 4.29 & 88.27 & 6.90 & NS \\
\hline 16 & Distance Prosthion to PM1 (PPM1) & 67.98 & 4.84 & 68.68 & 3.65 & 66.29 & 6.87 & NS \\
\hline 17 & Dental length (DL) & 136.99 & 9.61 & 138.56 & 5.70 & 133.23 & 15.28 & NS \\
\hline
\end{tabular}

NS Non significant, $* p<0.05, * * p<0.01$

\section{Results}

\section{Morphometrics}

The results and statistical differences of the skull measurements are shown in Tables 1 and 2. According to these results, the differences between males and females in BA, IBNB, SH, FMW, AO and IBPCW were statistically significant.

Table 2 Measurements of the skull of Sharri sheep

\begin{tabular}{|c|c|c|c|c|c|c|c|c|}
\hline \multirow[t]{2}{*}{$\mathrm{N}^{\mathrm{o}}$} & \multirow{2}{*}{$\begin{array}{l}\text { Dimension } \\
(\mathrm{mm})\end{array}$} & \multicolumn{2}{|l|}{ Total } & \multicolumn{2}{|l|}{ Female } & \multicolumn{2}{|l|}{ Male } & \multirow[t]{2}{*}{$p$ value } \\
\hline & & Mean & SD & Mean & SD & Mean & SD & \\
\hline 20 & Infraorbital foramen to Akrokranion (IFA) & 169.66 & 8.46 & 169.05 & 6.20 & 171.15 & 12.67 & NS \\
\hline 21 & Pre-facial width (PFW) & 75.24 & 5.65 & 76.16 & 4.30 & 73.02 & 7.87 & NS \\
\hline 22 & Orbital length (OL) & 41.21 & 1.99 & 41.07 & 1.52 & 41.56 & 2.91 & NS \\
\hline 23 & Orbital width (OW) & 37.71 & 1.84 & 37.46 & 1.61 & 38.31 & 2.28 & NS \\
\hline 24 & Orbital depth (OD) & 50.69 & 2.60 & 51.36 & 2.14 & 49.10 & 3.01 & $*$ \\
\hline 25 & Orbital margin of lacrimal bone (OMLB) & 21.69 & 2.05 & 21.57 & 2.21 & 21.98 & 1.67 & NS \\
\hline 26 & Orbital margin of zygomatic bone (OMZB) & 45.62 & 4.16 & 44.88 & 3.88 & 47.40 & 4.48 & NS \\
\hline 27 & Orbital margin of frontal bone (OMFB) & 59.00 & 3.36 & 59.33 & 3.46 & 58.20 & 3.12 & NS \\
\hline 28 & Orbit perimeter $(\mathrm{OP})$ & 126.31 & 5.79 & 125.78 & 5.54 & 127.58 & 6.48 & NS \\
\hline 29 & Foramen magnum height (FMH) & 18.31 & 1.18 & 18.56 & 1.09 & 17.71 & 1.21 & NS \\
\hline 30 & Foramen magnum width (FMW) & 21.04 & 1.67 & 21.45 & 1.21 & 20.03 & 2.20 & $*$ \\
\hline 31 & Akrokranion to Opisthion (AO) & 28.33 & 2.94 & 27.17 & 1.74 & 31.11 & 3.42 & $* *$ \\
\hline 32 & Inter condylar width (ICW) & 50.32 & 3.29 & 49.69 & 2.53 & 51.82 & 4.45 & NS \\
\hline 33 & Inter base paracondylar width (IBPCW) & 48.06 & 2.85 & 47.37 & 2.61 & 49.73 & 2,82 & $*$ \\
\hline 34 & Inter paracondylar width (IPCW) & 27.74 & 1.87 & 27.64 & 1.72 & 27.99 & 2,28 & NS \\
\hline 35 & Skull width (SW) & 103.47 & 5.91 & 103.75 & 4.09 & 102.81 & 9.20 & NS \\
\hline 36 & Greatest palatal width (GPW) & 67.18 & 4.59 & 67.77 & 3.27 & 65.75 & 6.84 & NS \\
\hline 37 & Upper molar row from PM1 - M3 (UMR) & 69.50 & 5.88 & 70.17 & 3.02 & 67.90 & 9.98 & NS \\
\hline
\end{tabular}

NS Non significant, * $p<0.05, * * p<0.01$ 
The most important difference was in AO. Male measurement values for AO were higher than that of females. SL and $\mathrm{SW}$ values were higher for females, while $\mathrm{SH}$ values were higher for males. However, the difference between these values was statistically insignificant. The parameters of foramen magnum in females were bigger than in male individuals and only the difference in foramen magnum width (FMW) was found to be statistically significant.

A correlation test was used with skull measurements. The strongest correlations were observed between the individual longitudinal dimensions of the skull. However, a correlation value between the FL and FW was also very high $(r=0.758)$. There was a negative correlation between the width and height of the foramen magnum and certain dimensions of the skull. The highest negative value was seen between FMW and OA $(r=-0.567)$. The correlation value between FMH and SH was -0.488 . These two correlations were statistically significant.

The width and length of the cornual processes in male animals were $35.9 \pm 12 \mathrm{~mm}$ and $151 \pm 78.98 \mathrm{~mm}$, respectively. The correlation between those parameters was very strong $(r=0.997)$. The correlation coefficient between SH and GLNB was also very high. The correlation value between SH and length of cornual processes was 0.961, the correlation value between the SH and width of cornual processes was 0.945 . The correlation coefficient between the greatest length of the nasal bone and the length of cornual processes was 0.956 , and correlation between GLNB and width of cornual processes was 0.973 .

The values for orbital measurements and the statistical differences between females and males are shown in Table 3. These differences in OD and the percentages of the frontal bone in the orbit perimeter were found to be statistically significant. There was no statistically significant difference in the other measurements of the orbit.

Dimensions of the mandible and the statistical difference levels between females and males are given in
Table 4. The mental foramen was situated almost in the middle of the diastema (Fig. 5). LARMF in females was $25.00 \mathrm{~mm} \pm 3.22$ and $22.18 \mathrm{~mm} \pm 2.37$ in males. This measurement is very helpful to determinate the correct position of the needle during the mental nerve anesthesia.

The distance of mandibular foramen from mandible angle were respectively $35.37 \mathrm{~mm} \pm 9.36$ and $31.87 \mathrm{~mm} \pm 3,27$ for females and males. Mandibular foramen is easy to access with the help of these two landmarks which are so practical and during the block of mandibular nerve (Fig. 6). The most important difference was seen in RBMFRMRM, ASL and LARMF. It was observed that the values of females were higher than males in mandible length (ML) as well as in skull length (SL), and these differences were statistically significant. It was observed that the diastema (D) was longer in females; however, the difference between sexes was not significant.

The results of indices are given in Table 5. FMI and OI were bigger in males, while other indices were higher in females. There was no statistical difference between male and female in all index values.

The widest parameter of the skull was the facial width (FW), respectively, $117.42 \mathrm{~mm} \pm 7.45$ in males and $120.32 \mathrm{~mm} \pm 4.86$ in females, with statistically significant difference between the sexes.

\section{Morphology}

In the skull of Sharri sheep as in all ruminants we can distinguish five surfaces: roof of the skull, nuchal plane, base of the skull and two lateral walls. The roof of the skull is formed by incisive, nasal and frontal bones (Fig. 1). The frontal bones comprise most of the roof with double supraorbital foramina in 14 samples (41\%) (in only one sample this foramen was very large). In 10 female skulls (29\% of the total samples) we observed a concave surface like fossa in

Table 3 Measurements of the orbit of Sharri sheep

\begin{tabular}{|c|c|c|c|c|c|c|c|c|}
\hline \multirow[t]{2}{*}{$\mathrm{N}^{\mathrm{o}}$} & \multirow{2}{*}{$\begin{array}{l}\text { Dimension } \\
(\mathrm{mm})\end{array}$} & \multicolumn{2}{|l|}{ Total } & \multicolumn{2}{|l|}{ Female } & \multicolumn{2}{|l|}{ Male } & \multirow[t]{2}{*}{$p$ value } \\
\hline & & Mean & SD & Mean & SD & Mean & SD & \\
\hline 22 & Orbital length (OL) & 41.21 & 1.99 & 41.07 & 1.52 & 41.56 & 2.91 & NS \\
\hline 23 & Orbital width (OW) & 37.71 & 1.84 & 37.46 & 1.61 & 38.31 & 2.28 & NS \\
\hline 24 & Orbital depth (OD) & 50.69 & 2.60 & 51.36 & 2.14 & 49.10 & 3.01 & $*$ \\
\hline 25 & Orbital margin of lacrimal bone (OMLB) & 21.69 & 2.05 & 21.57 & 2.21 & 21.98 & 1.67 & NS \\
\hline 26 & Orbital margin of zygomatic bone (OMZB) & 45.62 & 4.16 & 44.88 & 3.88 & 47.40 & 4.48 & NS \\
\hline 27 & Orbital margin of frontal bone (OMFB) & 59.00 & 3.36 & 59.33 & 3.46 & 58.20 & 3.12 & NS \\
\hline \multirow[t]{4}{*}{28} & Orbit perimeter $(\mathrm{OP})$ & 126.31 & 5.79 & 125.78 & 5.54 & 127.58 & 6.48 & NS \\
\hline & $\%$ of Lacrimal bone & 17.81 & 1.77 & 17.95 & 1.84 & 17.46 & 1.65 & NS \\
\hline & $\%$ of Zygomatic bone & 37.41 & 3.12 & 37.35 & 3.23 & 37.55 & 3.00 & NS \\
\hline & $\%$ of Frontal bone & 48.43 & 2.96 & 49.39 & 2.88 & 46.13 & 1.59 & $* *$ \\
\hline
\end{tabular}

NS Not significant. *: $P<0.05$. **: $P<0.01$ 
Table 4 Measurements of the mandible of Sharri sheep

\begin{tabular}{|c|c|c|c|c|c|c|c|c|}
\hline \multirow[t]{2}{*}{$\mathrm{Nr}$} & \multirow{2}{*}{$\begin{array}{l}\text { Dimension } \\
(\mathrm{mm})\end{array}$} & \multicolumn{2}{|l|}{ Total } & \multicolumn{2}{|l|}{ Female } & \multicolumn{2}{|l|}{ Male } & \multirow[t]{2}{*}{$P$ Value } \\
\hline & & Mean & SD & Mean & SD & Mean & SD & \\
\hline 1 & Mandible Length (ML) & 185.91 & 13.33 & 189.38 & 7.59 & 177.60 & 19.88 & $*$ \\
\hline 2 & Maximum Mandible High (MMH) & 105.83 & 7.67 & 106.85 & 6.50 & 103.39 & 9.91 & NS \\
\hline 3 & Mandible Base to Condylar Process (MBCP) & 75.12 & 6.24 & 76.72 & 4.36 & 71.26 & 8.42 & $*$ \\
\hline 4 & Mandible Notch to Coronoid Process (MICP) & 38.05 & 2.00 & 38.08 & 1.61 & 37.96 & 2.82 & NS \\
\hline 5 & M3 to Mandible Angle (M3MA) & 60.74 & 4.04 & 61.64 & 4.05 & 58.61 & 3.27 & $*$ \\
\hline 6 & Articular Surface Length (ASL) & 24.43 & 1.79 & 25.01 & 1.13 & 23.04 & 2.33 & $* *$ \\
\hline 7 & First Incisive Tooth to Mandible Angle (FITMA) & 186.75 & 12.06 & 188.83 & 8.13 & 181.76 & 18.04 & NS \\
\hline 8 & First Incisive Tooth to First Premolar (FITFPm) & 56.69 & 4.41 & 57.49 & 4.07 & 54.77 & 4.80 & NS \\
\hline 9 & Lateral Alveolar Root to Mental Foramen (LARMF) & 24.17 & 3.23 & 25.00 & 3.22 & 22.18 & 2.37 & $*$ \\
\hline 10 & Diastema (D) & 45.81 & 3.73 & 46.48 & 3.46 & 44.20 & 4.04 & NS \\
\hline 11 & Lower Molar Row, from PM1 to M3 (LMR) & 72.61 & 5.69 & 72.93 & 2.65 & 71.83 & 10.00 & NS \\
\hline 12 & $\begin{array}{l}\text { Rostral border of the mandibular foramen to ramus mandible } \\
\text { rostral margin (RBMFRMRM) }\end{array}$ & 17.41 & 1.62 & 17.91 & 1.50 & 16.21 & 1.26 & $* *$ \\
\hline 13 & Mandibular Foramen to Mandible Angle (MFMA) & 34.34 & 8.16 & 35.37 & 9.36 & 31.87 & 3.27 & NS \\
\hline 14 & Mandibular Foramen to Mandible Caudal Margin (MFMCM) & 16.22 & 1.91 & 16.15 & 1.79 & 16.38 & 2.26 & NS \\
\hline
\end{tabular}

NS Not significant. *: $P<0.05$. **: $P<0.01$

Table 5 Skull indices of Sharri sheep

\begin{tabular}{|c|c|c|c|c|c|c|c|c|}
\hline \multirow[t]{2}{*}{$\mathrm{N}^{\mathrm{o}}$} & \multirow[t]{2}{*}{ Index } & \multicolumn{2}{|l|}{ Total } & \multicolumn{2}{|c|}{ Female } & \multicolumn{2}{|l|}{ Male } & \multirow[t]{2}{*}{$p$ value } \\
\hline & & Mean & SD & Mean & SD & Mean & SD & \\
\hline 1 & Skull Index (SI) & 41.84 & 1.71 & 41.84 & 1.73 & 41.83 & 1.74 & NS \\
\hline 2 & Cranial Index (CI) & 50.64 & 2.11 & 50.74 & 2.08 & 50.41 & 2.29 & NS \\
\hline 3 & Facial Index (FI) & 82.07 & 3.87 & 82.44 & 3.73 & 81.19 & 4.26 & NS \\
\hline 4 & Foramen magnum Index (FMI) & 87.35 & 6.11 & 86.70 & 6.34 & 88.89 & 5.53 & NS \\
\hline 5 & Orbital Index (OI) & 91.54 & 3.06 & 91.24 & 3.36 & 92.26 & 2.11 & NS \\
\hline
\end{tabular}

NS Non significant, $* p<0.05, * * p<0.01$

the midline between two frontal bones rostrally to supraorbital foramina. All female skulls were without cornual processes and the small elliptic, smooth area-fossa postorbitalis, described by Gündemir et al. (2020) in Bardhoka sheep, was absent in all samples. In either site of frontal bones just behind the caudal wall of the orbits and on opposite sides of the supraorbital foramen, a large fossa was present in eight female skulls (23\%).

The nuchal plane was composed by squama and lateral parts of the occipital bone and the parietal plane of the parietal bone (Fig. 3). The foramen magnum almost round, was situated between two ellipsoid condyles. Inter base precondylar width (IBPCW) was significantly different between sexes (Table 2). The coronary suture was "V" shaped in all but eight females and two males (about 30\%), where it was instead straight (Fig. 7) similar to a goat's skull.

The base of the skull is formed by incisive, maxilla, palatine, pterygoid, sphenoid and occipital bones (Fig. 4). The muscular tubercles of occipital bone were very large and elongated in 15 cases (44\%). Rostrally and between two palatine processes of the maxilla in 9 samples (26\%) one elongated fossa was visible. In 10 skulls (30\%), the two vertical plates of the palatine bones joined in the mid line with its horizontal plate in a "V" shape, while the rest of the skulls joined in the shape between "V" and " $\mathrm{U}$.

Ventrally, two condyles were joined with a notch between them. A narrow intercondylar notch has been distinguished in eight skulls (about 24\%), and a large notch has been seen in eight samples. The rest (almost 50\%) of the samples were average.

In seven skulls (20\%), the oval foramen was very large and the sphenopalatine foramen was smaller. Other individuals had smaller oval foramen and very large sphenopalatine foramen. The muscular processes of the temporal bone were double in eight cases (24\%).

Lateral walls of the skull are formed by incisive, maxilla, zygomatic, lacrimal, parietal and temporal bones (Fig. 2). Only eight female skulls (23\%) had prominent 
Fig. 7 Different shape of the parieto-frontal suture of Sharri sheep. A. The suture between frontal bones and parietal plan of parietal bone like straight line; B. The suture like "V" shape

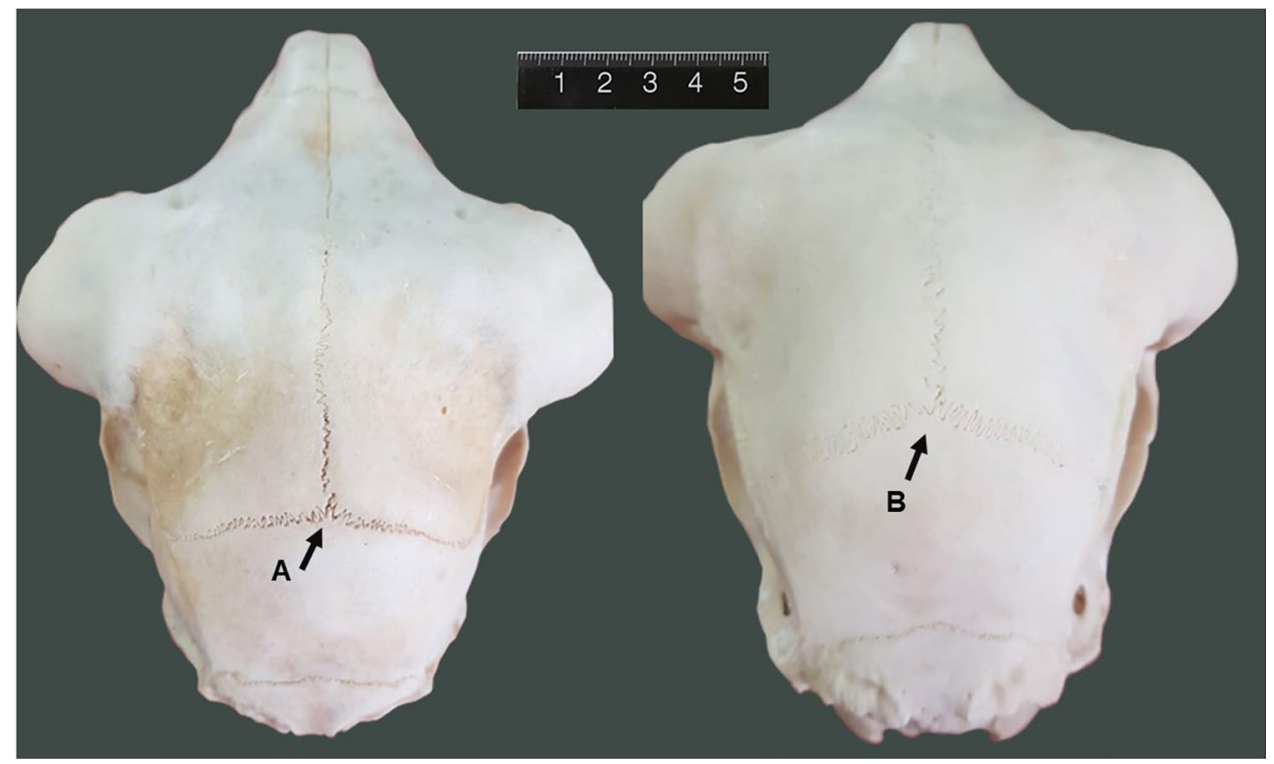

male profile, while none of the male skulls had a male profile. In the union of lacrimal bone, the maxilla and nasal bone on either side are elongated, and there is a narrow nasomaxillary fissure and nasolacrimal fissure (Constantinescu 2018). In 15 samples (44\%) these two fissures were fused and only in two cases small intra sutural bones between these two fissures were observed. On the lateral surface of the maxilla, multiple very large $(11-17 \mathrm{~mm})$ infraorbital foramina were located. In eight samples (23\%), they were smaller $(6-8 \mathrm{~mm})$ and round. In all skulls, a very prominent external lacrimal fossa was found between the lacrimal and zygomatic bones.

The orbits were well developed with almost equal vertical and horizontal diameters. The orbital ring was formed by: zygomatic bone ventrally (37.41\%), lacrimal bone rostrally $(17.81 \%)$ and frontal bone dorso-caudally - the biggest part (48.43\% of the total perimeter length) (Table 3). The frontal part of the orbits showed differences between the sexes.

Just laterally at the base of the zygomatic process of the temporal bone the osseous part of the external acoustic meatus was located (Constantinescu 2018; König and Liebich 2020).

\section{Discussion}

With the studies on the skeletal system, knowledge on taxonomy was obtained, and with the help of these measurements, the differences regarding gender analysis were revealed. In this study, 51 parameters were measured on the skull and mandible of the Sharri sheep. It was observed that 13 of these parameters made a statistical difference in sex determination. In addition, five different indices were evaluated and none of them were statistically different between females and males. The skull was also examined morphologically in the study. Sections that make a difference between male and female were specified.

The nasal bones were convex and the nasofrontal suture was between a "V" and " $U$ " shape, compare to the nasofrontal suture in Mehraban sheep which is "U" shaped (Karimi et al. 2011) or in Bardhoka sheep which is "V" shaped (Gündemir et al. 2020). The palatomaxillary suture was "V" shaped like in the Bardhoka (Gündemir et al. 2020).

Skull length (SL) is an important parameter and has therefore been evaluated in many studies. It is thought that this parameter may help taxonomic classification between species. In one study of Onuk et al. (2013) craniometric data of three species of ruminants were obtained, and the difference between these species was statistically evidenced. Similar observations were made in relation to European bison (Krasińska et al. 2008; Kobryńczuk et al. 2008a). It is stated in the literature that the parameter of skull length was $241.30 \pm 14.01 \mathrm{~mm}$ in Turkish-origin İvesi sheep (Y1lmaz and Demircioglu 2020), 241.20 $\pm 25.17 \mathrm{~mm}$ in Hemşin sheep (Dalga et al. 2018), 204.49 $\pm 9.71 \mathrm{~mm}$ in Morkaraman sheep and $198.09 \pm 7.69 \mathrm{~mm}$ in Tuj sheep (Özcan et al. 2010). In the study conducted in Trinidad, the skull length of Barbados Black Belly Sheep was $24.65 \pm 2.16 \mathrm{~cm}$ (Mohamed et al. 2016). In case of Iranian Mehraban sheep, the skull length was reported to be $20.06 \mathrm{~cm}$ (Karimi et al. 2011). It was said that this length was $325 \pm 9.9 \mathrm{~mm}$ in Yankasa rams of Nigerian origin (Shehu et al. 2019) and 265.51 $\pm 22.24 \mathrm{~mm}$ in Xisqueta sheep of Spain (Parés Casanova et al. 2010). In the Bardhoka sheep breed of Kosovo origin (Gündemir et al. 2020 ), this value is said to be $245.25 \pm 10.24 \mathrm{~mm}$ for females and $257.98 \pm 15.81 \mathrm{~mm}$ for males. 
The results of our study demonstrate that mean skull length of Sharri sheep is longer $(247.47 \pm 13.12 \mathrm{~mm})$ than Bardhoka female sheep (245.25 $\pm 10,24 \mathrm{~mm})$ (Gündemir et al. 2020), Hemshin sheep (241.20 $\pm 25.17 \mathrm{~mm})$, Morkaraman sheep $(204.49 \pm 9.71 \mathrm{~mm})$ and Tuj sheep (198.09 \pm 7.69 mm) (Özcan et al. 2010; Dalga et al. 2018), but smaller than Xisqueta sheep that was found to be $265.51 \pm 22.24 \mathrm{~mm}$ (Parés Casanova et al. 2010).

Yllmaz and Demircioglu (2020) stated that the widest place of the skull is the distance Ectorbitale-Ectorbitale, which in Ivesi sheep reaches $113.38 \pm 8.92 \mathrm{~mm}$ in males and $116.76 \pm 6.37 \mathrm{~mm}$ in females, however, the difference between sexes is statistically insignificant. In another study this parameter was $102.98 \pm 2.52 \mathrm{~mm}$ in Morkaraman sheep and $101.66 \pm 1.69 \mathrm{~mm}$ in Tuj sheep (Özcan et al. 2010).

The Skull Index in Sharri sheep was $41.84 \pm 1.71 \%$, quite similar to Bardhoka sheep (41.69 $\pm 1.74 \%$ ) (Gündemir et al. 2020), compared to $53.57 \%$ in Mehraban sheep (Karimi et al. 2011).

In anthropology, the foramen magnum dimensions are used in sex determination. Günay and Altinkök (2000) stated that the foramen magnum area is bigger in males than in females $\left(909.91 \pm 126.02 \mathrm{~mm}^{2}\right.$ and $819.01 \pm 117.24 \mathrm{~mm}^{2}$, respectively), and the difference is statistically significant. In another study by Gapert et al. (2009), it was mentioned that the shape of the foramen magnum is an important dimorphic feature. Apart from the area and direct measurements of the foramen magnum (Choudhary et al. 2020), an index applied using the width and height, and the effectiveness of the ratio between the sexes were studied in certain breeds of sheep. This index did not differ between sexes in İvesi sheep (Yllmaz and Demircioglu 2020). In our study, it was not observed that the foramen magnum index plays a decisive role in the sexual dimorphisms.

Mandibular measurements include osteometric parameters used in determining both species and sex. In a study conducted on sheep and deer, the differences between these two different species were revealed (Avdić et al. 2013). In a study on the mandible of Tuj and Morkaraman sheep, the differences between these two species were revealed (Demiraslan et al. 2014). The values of Tuj sheep were higher and statistically significant differences were revealed in this study. Özkan et al. (2020) revealed the difference between female and male individuals in their study on Bardhoka sheep using indices. In the present study, six of the 14 mandible dimensions were found to be statistically significant in sex determination. Mandible length of Sharri sheep was $185.91 \pm 13.33 \mathrm{~mm}$ compared to $15.76 \pm 2.25 \mathrm{~mm}$ of the Mehraban sheep (Karimi et al. 2012) and Iranian native sheep $14.08 \pm 0.01 \mathrm{~cm}$ (Monfared 2013). Diastema of Sharri sheep was very similar to that of Bardhoka female sheep, $45.81 \pm 3.73 \mathrm{~mm}$ and $45.98 \pm 3.87 \mathrm{~mm}$ (Özkan et al. 2020), respectively, but bigger than in Tuj (36.44 $\pm 2.5 \mathrm{~mm})$,
Morkaraman (37.16 $\pm 1.88 \mathrm{~mm})$ (Demiraslan et al. 2014) and Mehraban sheep (3.98 $\pm 0.48 \mathrm{~cm}$ (Karimi et al. 2012).

\section{Conclusions}

The results of this study are important in many respects: morphological, morphometrical and clinical because they can aid in local anesthesia of the mental, infraorbital and mandibular nerves during surgical procedures of the head region.

Since there is no information on these parameters in this sheep breed, the data of our study will be a strong baseline for further studies in comparative anatomy with other ruminants and in other fields like zooarchaeology and animal welfare.

Acknowledgements Many thanks to DVM Rami Selmani from Tetovo, Republic of North Macedonia who assisted us in our study with the collection and preparation of Sharri sheep skull samples.

Data availability The data that support the findings of this study are available from the corresponding author upon reasonable request.

\section{Declarations}

Conflict of interest The authors declare no potential conflicts of interests with respect to the research, authorship, and/or publication of this article.

Open Access This article is licensed under a Creative Commons Attribution 4.0 International License, which permits use, sharing, adaptation, distribution and reproduction in any medium or format, as long as you give appropriate credit to the original author(s) and the source, provide a link to the Creative Commons licence, and indicate if changes were made. The images or other third party material in this article are included in the article's Creative Commons licence, unless indicated otherwise in a credit line to the material. If material is not included in the article's Creative Commons licence and your intended use is not permitted by statutory regulation or exceeds the permitted use, you will need to obtain permission directly from the copyright holder. To view a copy of this licence, visit http://creativecommons.org/licenses/by/4.0/.

\section{References}

Avdić R, Hadžiomerović N, Tandir F, Bejdić P, Ćutahija V (2013) Analysis of morphometric parameters of the roe deer mandible (Capreolus capreolus) and mandible of the sheep (Ovis aries). Veterinaria (Sarajevo) 62:1-9

Bytyqi H, Baumung R, Mehmeti H, Fuerst-Waltl B (2014) Phenotypic characterization and description of production systems of autochthonous sheep breeds in Kosovo. Anim Genet Resour Inf 54:163-170. https://doi.org/10.1017/S2078633614000034

Choudhary OP, Priyanka P, Kalita PC, Arya RS, Kalita A, Doley PJ (2020) A morphometrical study on the skull of goat (Capra hircus) in Mizoram. Int J Morphol 38:1473-1478. https://doi.org/10. 4067/S0717-95022020000501473 
Constantinescu GM (ed) (2018) Illustrated veterinary anatomical nomenclature, 4th edn. Georg Thieme Verlag, Stuttgart

Dalga S, Aslan K (2020) Topographic and morphometric study on mental foramen in Hemshin sheep for local anesthesia. MJAVL 10:93-97

Dalga S, Aslan K, Akbulut Y (2018) A morphometric study on the skull of the adult Hemshin sheep. Van Vet J 29:125-129

Demiraslan Y, Gülbaz F, Özcan S, Dayan Orhun M, Akbulut Y (2014). Morphometric analysis of the mandible of Tuj and Morkaraman sheep. JVA 7:75-86. https://doi.org/10.21608/JVA.2014.44813

Dzabirski V, Porchu K, Martinovska Stojchesk A, Belichovska K, Janeska-Stamenkovska I, Milevska J (2013) Determination of agri-environmental supporting rates to protect biodiversity of indigenous sheep breeds.https://doi.org/10.7251/AGSY130312 41D

Gapert R, Black S, Last J (2009) Sex determination from the foramen magnum: discriminant function analysis in an eighteenth and nineteenth century British sample. Int J Legal Med 123:25-33. https://doi.org/10.1007/s00414-008-0256-0

Günay Y, Altinkök M (2000) The value of the size of foramen magnum in sex determination. J Clin Forensic Med 7:147-149. https://doi. org/10.1054/jcfm.2000.0430

Gündemir O, Duro S, Jashari T, Kahvecioğlu O, Demircioğlu I, Mehmeti H (2020) A study on morphology and morphometric parameters on skull of the Bardhoka autochthonous sheep breed in Kosovo. Anat Histol Embryol 49:365-371. https://doi.org/10. 1111/ahe. 12538

Karimi I, Onar V, Pazvant G, Hadipour M, Mazaheri Y (2011) The cranial morphometric and morphologic characteristics of Mehraban sheep in Western Iran. Glob Vet 6:111-117

Karimi I, Hadipour M, Nikbakht P, Motamedi S (2012) The lower jawbone of Mehraban sheep: A descriptive morphometric approach. World's Vet J 2:57-60

Kobryńczuk F, Krasińska M, Szara T (2008a) Polarization of skull shapes in adult lowland European bison, Bison bonasus bonasus. Ann Zool Fennici 45:341-346. https://doi.org/10.5735/086.045. 0416

Kobryńczuk F, Krasińska M, Szara T (2008b) Sexual dimorphism in skulls of the lowland European bison, Bison bonasus bonasus. Ann Zool Fennici 45:335-340. https://doi.org/10.5735/086.045. 0415

König HE, Liebich HG (2020) Veterinary anatomy of domestic animals. Textbook and color atlas, 7th edition. Thieme Verlag, Stuttgart-New York

Krasińska M, Szuma E, Kobryńczuk F, Szara T (2008) Morphometric variation of the skull during postnatal development in the lowland European bison Bison bonasus bonasus. Acta Theriol 53:193216. https://doi.org/10.1007/BF03193117

Kugler W (2009) Rare breeds and varieties of the Balkan-Atlas 2009. Monitoring Institute for Rare Breeds and Seeds in Europa, SAVE Foundation
Marzban AB, Hajian O, Rahmati S (2018) Investigating the morphometric characteristics of male and female Zell sheep skulls for sexual dimorphism. ASJ 15:13-20

Mohamed R, Driscoll M, Mootoo N (2016) Clinical anatomy of the skull of the Barbados Black Belly sheep in Trinidad. Int J Curr Res Med Sci 2:8-19

Monfared AL (2013) Clinical anatomy of the skull of Iranian native sheep. Glob Vet 10:271-275. https://doi.org/10.5829/idosi.gv. 2013.10.3.7253

N. A. V. (2017) The International Committee on Veterinary Gross Anatomical Nomenclature. Published by the Editorial Committee Hannover (Germany), Columbia, MO (USA), Ghent (Belgium), Sapporo (Japan), 6th edition (Revised version).

Onar V, Pazvant G, Pasicka E, Armutak A, Alpak H (2015) Byzantine horse skeletons of Theodosius Harbour: 2. Withers height estimation. Rev Med Vet 166:30-42

Onuk B, Kabak M, Atalar K (2013) Anatomic and craniometric factors in differentiating roe deer (Capreolus capreolus) from sheep (Ovis aries) and goat (Capra hircus) skulls. Arch Biol Sci 65:133-141. https://doi.org/10.2298/ABS1301141M

Özcan S, Aksoy G, Kürtül I, Aslan K, Özüdogru Z (2010) A comparative morphometric study on the skull of the Tuj and Morkaraman sheep. Kafkas Universitesi Veteriner Fakultesi Dergisi 16:111114. https://doi.org/10.9775/KVFD.2009.518

Özkan E, Jashari T, Gündemir O, Gezer İnce N (2020) Morphometric analysis of the mandible of Bardhoka autochthonous sheep in Kosovo. Anat Histol Embryol 49:737-741. https://doi.org/10. 1111/ahe. 12568

Parés Casanova PM, Sarma K, Jordanai Vidal J (2010) On biometrical aspects of the cephalic anatomy of Xisqueta sheep (Catalunya, Spain). Int J Morphol 28:347-351. https://doi.org/10.4067/S071795022010000200001

Shehu SA, Bello A, Danmaigoro A, Abdulrasheed HA, Atabo SM, Mahmud MA (2019) Osteometrical study on age related changes of the skull of Yankasa ram. JASVM 4:71-77. https://doi.org/10. 31248/JASVM2019.132

Von den Driesch, A. (1976). A guide to the measurement of animal bones from archaeological sites: as developed by the Institut für Palaeoanatomie, Domestikationsforschung und Geschichte der Tiermedizin of the University of Munich (Vol. 1). Peabody Museum Press.

Wehausen JD, Ramey RR (2000) Cranial morphometric and evolutionary relationships in the northern range of Ovis canadensis. J Mammal 81:145-161. https://doi.org/10.1644/1545-1542(2000) 081\%3c3C0145:CMAERI\%3e3E2.0.CO;2

Y1lmaz B, Demircioglu İ (2020) İvesi Koyunlarda (Ovis aries) Kafatasının Morfometrik Analizi. Fırat Üniversitesi Sağlık Bilimleri Veteriner Dergisi 34:01-06

Publisher's note Springer Nature remains neutral with regard to jurisdictional claims in published maps and institutional affiliations. 